\title{
Desenvolvimento de metodologia expedita para avaliação de impactos ambientais em microbacia do rio Paraíba do Sul
}

\section{Development of an expeditious methodology to evaluate environmental impacts in microbasin at Paraíba do Sul river}

\author{
1 Francisco Jácome Gurgel Júnior gurgel.jr@gmail.com \\ 2 Pedro França Magalhães \\ 3 Renato Donato Viana \\ ${ }^{4}$ Mariana Avila Corrêa Cardoso de Oliveira
}

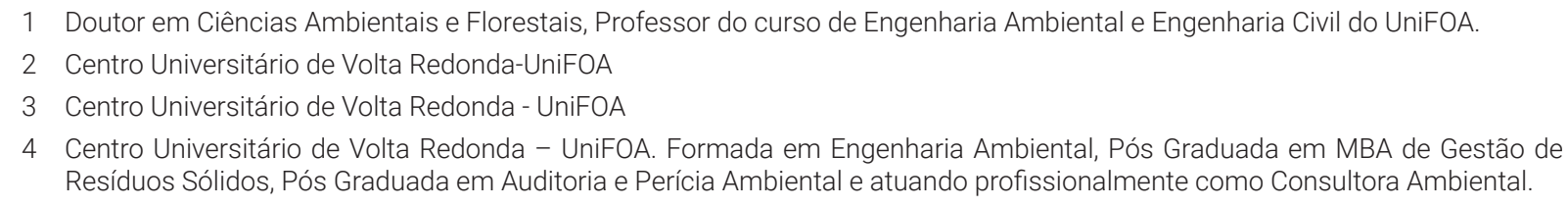

\section{Resumo}

A bacia hidrográfica é a unidade territorial de planejamento prevista pela Política Nacional de Recursos Hídricos (Lei Federal n 9.433/97) para gestão dos recursos hídricos e ocupação irregular pela ação antrópica e tem sido responsável pela ocorrência de inúmeros impactos ambientais negativos sobre os recursos ambientais existentes. A proposta deste estudo visa suprir a necessidade do estabelecimento de métodos simplificados que auxiliem a tomada de decisão pelo gestor ambiental. Para isso, foi criada uma metodologia expedita a partir de ferramentas simples e de fácil acesso. Essa metodologia é de grande importância para auxiliar na tomada de decisão dos gestores ambientais e de técnicos dos órgãos fiscalizadores na busca pela proteção das bacias hidrográficas e mitigação dos impactos ambientas negativos provenientes do uso e ocupação desordenada do solo. 0 desenvolvimento da metodologia foi embasado em um referencial teórico da legislação ambiental vigente, referente ao uso e ocupação do solo, bacias hidrográficas, zoneamento municipal e demarcação de faixa marginal de proteção, utilizando o rio Bugio para demonstração. A aplicação do método foi realizada através da coleta de dados primários, utilizando-se ferramentas de fácil acesso, como os dados fornecidos pelo site do IBGE (Instituto Brasileiro de Geografia e Estatística) e pelo sistema de localização geográfica (geographiclocation) do AutoCAD. Com a coleta desses dados, foi possível realizar um diagnóstico da bacia hidrográfica.

\section{Palavras-chave:}

Bacia hidrográfica. Ferramentas de gestão. Impactos ambientais. Rio Bugio.

\begin{abstract}
The hydrographic basin is the territorial planning unit provided by the National Water Resources Policy (Federal Law 9333/97) for the management of water resources and the irregular occupation by anthropic action and it has been responsible for the occurrence of numerous negative environmental impacts on resources. The purpose of this study is to meet the need of establishing simplified methods in order to help the environmental manager decision making. Thus, an expeditious methodology based on simple and easily accessible tools was created. This methodology will be of great importance to assist in the decision making of the environmental managers and technicians at the inspection agencies searching for the protection of the watersheds and mitigation of the negative environmental impacts arising from the use and disordered occupation of the soil. The development of the methodology was based on a theoretical reference of the current environmental legislation, regarding the use and occupation of the soil, hydrographic basins, municipal zoning and demarcation of the marginal strip of protection and the river Bugio was used to demonstrate it. The application of the method was done through the collection of primary data, using easily accessible tools, such as the data provided by the IBGE (Brazilian Institute of Geography and Statistics) and the geographic localization system of AutoCAD. With the collection of these data, it was possible to make a diagnosis of the river basin.
\end{abstract}

\section{Keywords:}

Hydrographic basin. Management tools. Environmental impacts. Rio Bugio.

\section{Como você deve citar?}

GURGEL JÚNIOR, Francisco Jácome et al. Desenvolvimento de metodologia expedita para avaliação de impactos ambientais em microbacia do rio Paraíba do Sul. Cadernos UniFOA, Volta Redonda (RJ), v. 16, n. 46, p. 1-12, ago, 2021. 


\section{INTRODUÇÃO}

A insuficiência de metodologias simplificadas de avaliação de impactos ambientais que auxiliem a sociedade no monitoramento das bacias hidrográficas é um dos fatores que contribuem para a má gestão dos recursos hídricos em nível global e, consequentemente, para a ocorrência de impactos ambientais deletérios sobre essas bacias. A Política Nacional do Meio Ambiente (Lei Federal nº 6.938/81) prevê no seu artigo $9^{\circ}$, inciso III, a avaliação de impacto ambiental (AIA), que é um instrumento importante, mas que requer tempo e estudos adicionais para sua elaboração e diagnóstico. A avaliação da degradação ambiental em uma microbacia do rio Paraíba do Sul, utilizando-se metodologia expedita é uma proposta simples e acessível que permite que técnicos integrantes do Poder Público, nas três esferas de governo, utilize ferramentas digitais de fácil acesso e manuseio, realizando a delimitação da microbacia e/ou bacia hidrográfica, a obtenção de informações relativas ao uso do solo, tais como: áreas edificadas, áreas passíveis de serem recuperadas e áreas degradadas para o monitoramento, como também a prática de ações de manejo voltadas para sua devida proteção. De posse desses dados, é possível gerar um diagnóstico preciso da bacia hidrográfica e a coleta de indicadores diversos imprescindíveis ao monitoramento ambiental e a tomada de decisão que promovam ações de recuperação da área avaliada. Com o uso das ferramentas disponíveis e aplicação da técnica proposta, será possível, em uma escala de 1:50000, a realização de cálculos dos índices de ocupação do solo, índice de degradação, densidade populacional, estimativa de poluição, entre outros. A metodologia proposta reúne informações obtidas no site do IBGE, utilização de aplicativos de livre acesso e Software para tratamento dos dados, oferecendo diversos benefícios, como a redução de custos com deslocamentos in loco, redução de tempo, praticidade e agilidade durante a elaboração dos trabalhos e relatórios acerca das áreas a serem fiscalizadas pelos órgãos ambientais federais, estaduais e municipais integrantes do Sistema Nacional de Meio Ambiente (SISNAMA).

\section{METODOLOGIA}

O método proposto foi pensado e desenvolvido a partir de uma pesquisa sobre a legislação ambiental vigente relacionada ao uso e ocupação do solo, dos conceitos advindos da Política Nacional de Recursos Hídricos (Lei Federal n 9.433/97), considerando-se a bacia hidrográfica como unidade de gestão e planejamento e, secundariamente, as ferramentas utilizadas para o desenvolvimento e aplicação da metodologia em campo. Todos os procedimentos adotados para a elaboração dessa metodologia foram baseados no uso de ferramentas simples, de fácil e amplo acesso, justificando a indicação de aplicação por técnicos que atuam no gerenciamento, fiscalização e monitoramento de recursos hídricos. Para a demonstração da metodologia e seu desenvolvimento, foi escolhida a microbacia do rio Bugio, afluente da margem rio Paraíba do Sul, localizado no Bairro Siderlândia, município de Volta Redonda/ RJ. O rio Paraíba do Sul é o corpo receptor natural de toda a malha hidrográfica inserida nos limites do município de Volta Redonda. Desenvolve-se por $1.145 \mathrm{~km}$ e do total drenado, $168 \mathrm{~km}^{2}$ correspondem ao município, ou seja, 0,3\% da bacia (FEEMA, 1991). A bacia do rio Paraíba do Sul drena cerca de 55.400 $\mathrm{km}^{2}$, uma área 1,3 vezes maior do que a área de todo o território do Estado do Rio de Janeiro (43.000 $\mathrm{km}^{2}$ ) e engloba parte dos estados do Rio de Janeiro (21.000 km²), São Paulo (13.500 km²) e Minas Gerais $\left(20.900 \mathrm{~km}^{2}\right)$, (FEEMA, 1991). O trecho do rio Paraíba do Sul situado em Volta Redonda está inserido no chamado curso médio inferior, que vai de Cachoeira Paulista até São Fidélis e possui uma extensão aproximada de $430 \mathrm{~km}$. Apresenta segmentos encachoeirados, cuja declividade média alcança pouco mais de $1 \mathrm{~m} / \mathrm{km}$, seguindo a direção noroeste, com leito arenoso. 


\subsection{Legislação}

Foram aplicadas diretrizes estabelecidas pela Lei Federal $n^{\circ}$ 9.433/97, que instituiu a Política Nacional de Recursos Hídricos, a Lei do Plano Diretor de Volta Redonda e o Decreto Estadual n 42.356 , de 2010, que trata da delimitação da Faixa Marginal de Proteção (FMP). A base legal aplicada nesse método serve de parâmetro para a escolha dos indicadores que vão estabelecer o grau de comprometimento ambiental da bacia em estudo, a relação entre o uso e a ocupação do solo, os reais padrões de uso e ocupação do solo e o comprometimento da FMP. O conhecimento e cumprimento da legislação vigente são de fundamental importância para a proteção do meio ambiente e é uma forma de estabelecimento de regras que tem como objetivo maior a garantia da qualidade ambiental dos recursos naturais e, por consequência, a melhor qualidade de vida nos centros urbanos.

\subsubsection{Política Nacional de Recursos Hídricos}

Segundo Silveira (apud CARDOSO et al., 2006), a bacia hidrográfica é definida como uma área de captação natural da água da precipitação, convergindo os escoamentos para um único ponto de saída, composta de um conjunto de superfícies vertentes e de uma rede de drenagem formada por cursos d'água que confluem até resultar em um leito único no exutório. De acordo com Tucci \& Mendes (2006, p.15), os processos hidrológicos na bacia hidrográfica possuem duas direções predominantes de fluxo na bacia: vertical e o longitudinal. 0 vertical é representado pelos processos de precipitação, evapotranspiração, umidade e fluxo no solo, enquanto que o longitudinal pelo escoamento na direção dos gradientes da superfície e do subsolo. As bacias urbanizadas possuem sua ocupação consolidada, atingindo até mesmo as margens, planícies de inundação e a calha do rio, tendo como reflexo um círculo de baixa qualidade de vida da população, do ambiente urbano e do ambiente natural. Geralmente, a ocupação urbana desordenada avança sobre áreas sem condições mínimas de habitação e sujeitas a enchentes naturais e, nesse caso, a perda econômica passa a ser frequente. As mudanças significativas no ciclo hidrológico da bacia são o resultado da ocupação desordenada e as bacias passam a ser estudadas segundo as leis da hidrologia urbana. Nesse caso, a parcela do escoamento superficial da água da chuva é aumentada, tendo as inundações inclusive de áreas, onde não existiam problemas de alagamentos, como consequência (MAGALHÃES, 2013, p. 41 e 42). A Lei Federal n. ${ }^{\circ}$ 9.433/97 considera que a bacia hidrográfica é a unidade territorial para implementação da Política Nacional de Recursos Hídricos. A elaboração dos planos de recursos hídricos, que sugere o diagnóstico da situação atual dos recursos hídricos, a análise de alternativas de crescimento demográfico, o levantamento da evolução de atividades produtivas e de modificações dos padrões de ocupação do solo é construído a partir da delimitação da bacia hidrográfica.

\subsubsection{Plano Diretor de Volta Redonda}

Segundo o zoneamento municipal de Volta Redonda, a região delimitada pela bacia hidrográfica do rio Bugio encontra-se em uma ZHP (Zona Produção/Habitação), ZPH (Zona Habitação/Produção) e AIS (Áreas de Interesse Social). De acordo com o Decreto Municipal n. ${ }^{\circ}$ 978/78, a zona de produção/ habitação (ZPH) é onde a habitação é admitida e, embora a ocupação deva ser induzida para o uso industrial, nessa circunstância, serão adequadas as de produção fabril. A zona de habitação/produção (ZHP) é onde o uso de solo em nível de habitação é predominante, embora sejam tolerados as ocupações industriais e áreas de interesse social (AIS), áreas com legislação específica, de cunho eminentemente social e fins habitacionais, para atendimento às populações de baixa renda. A tabela 1 apresenta os índices de zoneamento para o Município de Volta Redonda. 
Tabela 1 - Índices de zoneamento para o Município de Volta Redonda

\begin{tabular}{|c|c|c|c|c|c|c|c|}
\hline Zonas & & $\begin{array}{l}\text { Taxa de } \\
\text { ocupação }\end{array}$ & $\begin{array}{c}\text { Coef. de } \\
\text { aproveitamento }\end{array}$ & $\begin{array}{l}\text { Quota de ter.p/ } \\
\text { habitação }\end{array}$ & $\begin{array}{l}\text { Afastamento } \\
\text { frontal }\end{array}$ & $\begin{array}{c}\text { Afastamento } \\
\text { lateral }\end{array}$ & $\begin{array}{l}\text { Afastamento } \\
\text { de fundos }\end{array}$ \\
\hline \multirow{2}{*}{ ZHX-1 } & $\mathrm{A}$ & $70 \%$ & 4 & 90 & 3,00 & 1,50 * & $2,5^{\star \star}$ \\
\hline & $\mathrm{T}$ & $50 \%$ & 1 & - & 3,00 & 1,50 * & $2,5^{\star \star}$ \\
\hline \multirow{2}{*}{ ZHP } & $\mathrm{A}$ & $70 \%$ & 4 & 90 & 3,00 & $1,5^{\star}$ & $2,5^{\star \star}$ \\
\hline & $\mathrm{T}$ & $60 \%$ & 1,5 & - & 3,00 & $1,5^{*}$ & $2,5^{\star \star}$ \\
\hline \multirow{2}{*}{ ZPH } & $\mathrm{A}$ & $80 \%$ & 1 & - & 3,00 & $1,50 *$ & $2,5^{\star \star}$ \\
\hline & $\mathrm{T}$ & $50 \%$ & 3 & 90 & 3,00 & 1,50 * & $2,5^{\star \star}$ \\
\hline \multirow{2}{*}{ ZA-2 } & $\mathrm{A}$ & $70 \%$ & 4 & 90 & \multirow{2}{*}{$c$} & $\mathrm{c}$ & \multirow{2}{*}{$b$} \\
\hline & $T$ & $40 \%$ & 1 & 125 & & a & \\
\hline \multirow{2}{*}{ ZEI } & $\mathrm{A}$ & & & \multirow{2}{*}{\multicolumn{3}{|c|}{ ÁREAS DE LEGISLAÇÃO ESPECÍFICA }} & \\
\hline & $\mathrm{T}$ & & & & & & \\
\hline AIS & $\frac{A}{T}$ & & & \multicolumn{3}{|c|}{ ÁREAS DE LEGISLAÇÃO ESPECÍFICA } & \\
\hline
\end{tabular}

Fonte: Decreto Municipal no 978/78 - Regulamenta o Sub-Zoneamento da ZH-

$X$, criada pelo Decreto Municipal nº 942/77 e dá outras providências.

Legenda referente a tabela 1.

\begin{tabular}{ll}
\hline A & Uso adequado. \\
\hline T & Uso tolerado. \\
\hline a & Não definido. \\
\hline b & Proporcional ao número de pavimentos conforme o Artigo $8^{\circ}$ da Lei Municipal 1412. \\
\hline c & Sem afastamento até o $3^{\circ}$ pavimento, se esses forem ocupados por uso comercial exclusivo ou misto. \\
\hline $\begin{array}{ll}\text { Art. } & 8^{\circ} \text { da Lei Municipal } 1412 \text { e, ainda, disposto no mesmo artigo, acima do último pavimento } \\
\text { ocupado de uso comercial, exclusivo, estando este último abaixo do terceiro pavimento. }\end{array}$ \\
\hline$*$ & Dispensado desde que acrescidos dos afastamentos de frente e fundos de $2,00 \mathrm{~m}$. \\
\hline$* *$ & $\begin{array}{l}\text { Dispensados desde que acrescidos os afastamentos laterais de } 1,00 \mathrm{~m} \\
\text { ou dispensados em } 50 \%, \text { quando houver empena cega. }\end{array}$ \\
\hline
\end{tabular}

\subsubsection{Faixa Marginal de Proteção}

De acordo com o Decreto Estadual n. ${ }^{\circ}$ 42.356/10, no que tange à Faixa Marginal de Proteção (FMP) e à legislação ambiental, os critérios para a demarcação da FMP estão associados ao uso da água para o abastecimento público das grandes cidades e para as atividades agrícolas e industriais. A área em questão se localiza em zona urbana do município e encontra-se antropizada, apresentando longa e consolidada ocupação urbana, com a existência de equipamentos de infraestrutura urbana, maIha viária com canalização de águas pluviais, rede de abastecimento de água e esgoto, distribuição de energia elétrica e iluminação pública, recolhimento de resíduos sólidos urbanos, tratamento de resíduos sólidos urbanos e elevada densidade demográfica. Ao longo da FMP da bacia, apresenta uma função ecológica escassa, devido à ocupação consolidada das margens do curso d'água a montante e a jusante do trecho analisado, impermeabilização da FMP, capeamento do curso d'água, sendo que a alternativa de recuperação da área como um todo é inviável pelos custos excessivos para a coletividade e para o Poder Público local. Segundo a classificação do zoneamento, as áreas destinadas à faixa marginal de proteção do rio Bugio e seus contribuintes estão compostas, em maior extensão, pelas ZPH e ZHP. Os planos de recursos hídricos analisam alternativas para crescimento demográfico e evolução de atividades produtivas por bacia hidrográfica. Quanto à elevada densidade demográfica, o decreto estadual permite a demarcação da faixa marginal de proteção com limites inferiores ao novo Código Florestal (Lei Federal n 12.651/12), desde que exista a consolidação de margem, inexistência ou impossibilidade de recuperação das funções ecológicas. 


\subsection{Instrumentos}

Para o desenvolvimento do método, foi necessária a utilização de carta topográfica fornecida pelo IBGE para coleta de informações de fonte fidedigna da região a ser analisada, representando toda a bacia hidrográfica composta pelo afluente principal e seus contribuintes.

O software AutoCAD foi utilizado através do recurso de localização geográfica para georreferenciar a imagem via satélite juntamente com a carta topográfica, visando ao cálculo dimensional das áreas passíveis de serem recuperadas e não preservadas da bacia hidrográfica.

\subsubsection{Cartografia}

Documentos cartográficos são informações valiosas e que ajudam a compreender e analisar fatos, acontecimentos e fenômenos que ocorrem na superfície da Terra. Essas informações são de grande relevância, quando associadas a um sistema de gestão de imagens cartográficas. Um sistema de software que vêm ganhando vários adeptos, motivados principalmente por sua versatilidade, é o Sistema de Informação Geográfica (SIG). No Brasil, a maioria das Cartas Topográficas (CT) foram elaboradas e confeccionadas no início da década de 1960 até meados da década de 1980 pelo Instituto Brasileiro de Geografia e Estatística (IBGE) ou pela Diretoria de Serviço Geográfico do Exército (DSG), órgãos responsáveis pelo levantamento e divulgação de informações sobre o território brasileiro (MELO et al., 2014, p. 192 e 193). A Carta Topográfica é uma representação em escala da superfície terrestre, de forma mensurável, projetando posições planimétricas e altimétricas. As posições altimétricas ou de relevo permitem demonstrar as curvas de nível e cotas, e as posições planimétricas demonstram uma projeção plana, fornecendo informações relativas a medições feitas na horizontal. São ferramentas importantes em projetos de pesquisa, sendo utilizadas para fornecer informações reais e precisas das condições naturais e artificiais do sistema terrestre.

\subsubsection{Escala}

Pesquisas de cunho geográfico, cartográfico, ambiental ou qualquer outra que se realize sobre o espaço físico de atuação de um fenômeno, espacializando a sua representação, e seus conceitos serão sempre representados em mapas e cartas com uma indicação de escala. A primeira e mais imediata definição para escala é dada pela conotação cartográfica, através de uma simples razão de semelhança, indicando a razão entre comprimentos no mapa e seu correspondente no mundo real (MENEZES; NETO, 1999). A escala permite a representação em relação à proporção entre a área real e a área representada no papel, podendo ser representada de forma numérica ou gráfica. A forma numérica, em formato de fração, onde o numerador indica a distância no mapa e a distância real correspondente, sempre em centímetros $(\mathrm{cm})$. A forma gráfica é representada em formato de uma reta dividida em segmentos, onde cada segmento apresenta uma distância, informando de maneira direta e correspondente entre as distâncias representadas e as reais da superfície cartografada.

\subsubsection{Computer Aided Drafting (CAD) - Desenho Assistido por Computador}

Segundo, Yoshida (2002 apud SPECK, 2005, p. 82), os sistemas CAD/CAM nasceram para melhorar os desenhos de prancheta e evoluíram. Hoje o CAD não é mais somente uma ferramenta para projetos, pois leigos sem formação técnica podem aprender a utilizá-lo profissionalmente a partir de cursos com duração de menos de 40 horas. Podemos destacar vários softwares CAD utilizados para captura e apresentação de mapas. $O$ AutoCAD é o mais conhecido, porém podemos citar outros, como, AutoCAD MAP 3D, GstarCAD, ZWCAD, IntelliCAD, BricsCAD. 


\subsection{Aplicação do método}

O método consiste em combinar o preconizado na legislação ambiental vigente com a utilização das ferramentas expeditas. Considerando a bacia hidrográfica como uma unidade de gestão territorial, a aplicação do método foi realizada com a utilização de dados primários para gerar os dados secundários. Por meio dessa metodologia, utilizamos as cartas topográficas extraídas do IBGE e o sistema de localização geográfica do AutoCAD para auxiliar na delimitação da Bacia Hidrográfica, sendo possível gerar dados da Região Hidrográfica, bem como o uso e ocupação do solo, dimensionamento de áreas passíveis de serem recuperadas e não preservadas e o estudo das faixas marginais de proteção. A bacia hidrográfica foi fracionada e estudada pontualmente.

\subsubsection{Unidade de Gestão}

A construção foi iniciada com o recorte da carta topográfica FL SF-23-Z-A-V-2, escala 1:50000, fundamentada através da delimitação da região por Bacia Hidrográfica presente da carta topográfica, conforme apresentado na figura 1 .

Figura 1 - Carta topográfica da Região Sudeste do Brasil

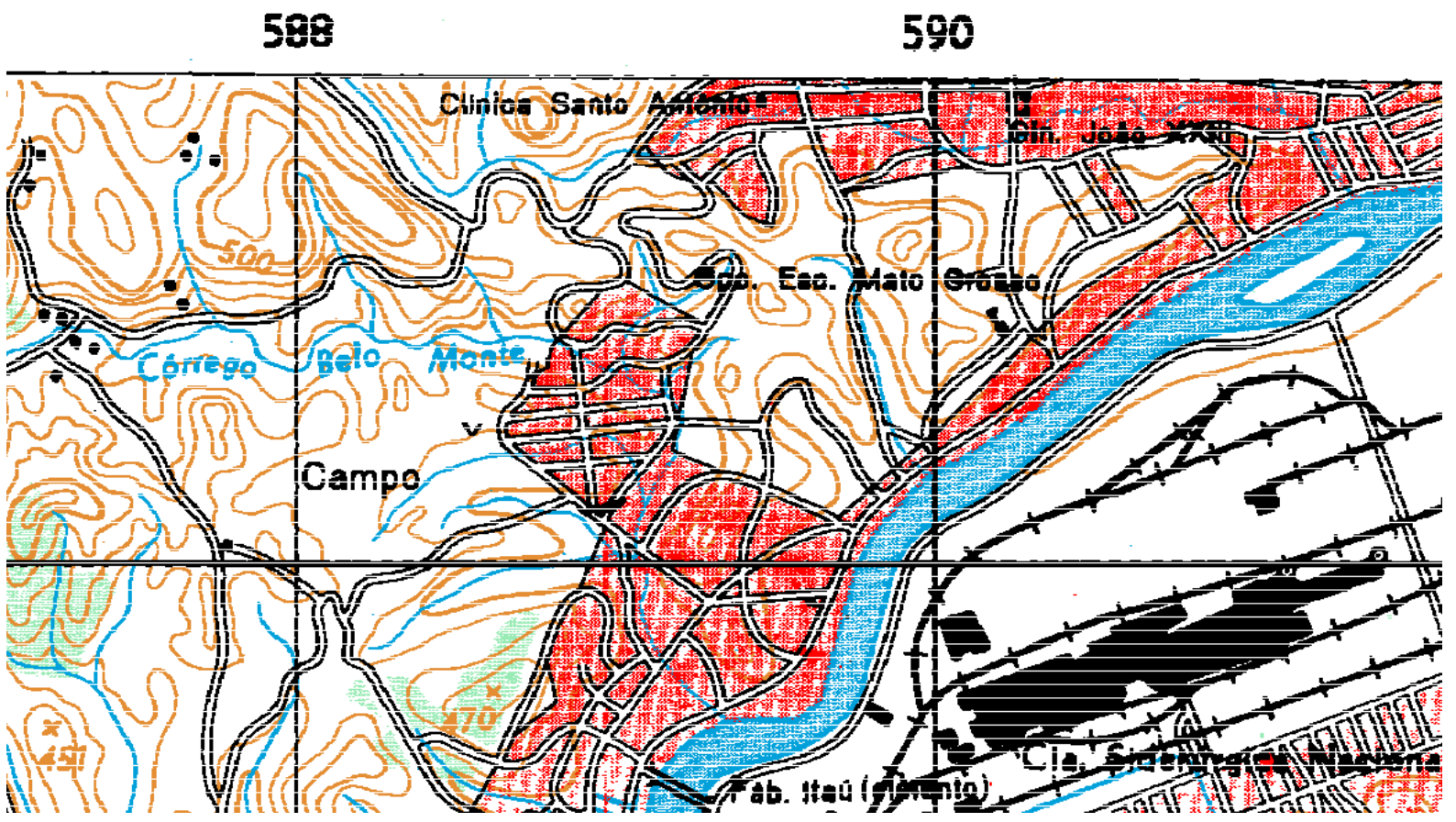

Fonte: IBGE - Instituto Brasileiro de Geografia e Estatística.

A metodologia foi iniciada com consulta e busca de informações fornecidas pelo IBGE através da Carta FL SF-23-Z-A-V-2, representada em escala 1:50000, suficiente para a aplicação no método desenvolvido. A Bacia Hidrográfica foi traçada e delimitada com a obtenção da carta topográfica, conforme mostra a figura 2 . 
Figura 2 - Carta topográfica com a delimitação da Bacia Hidrográfica

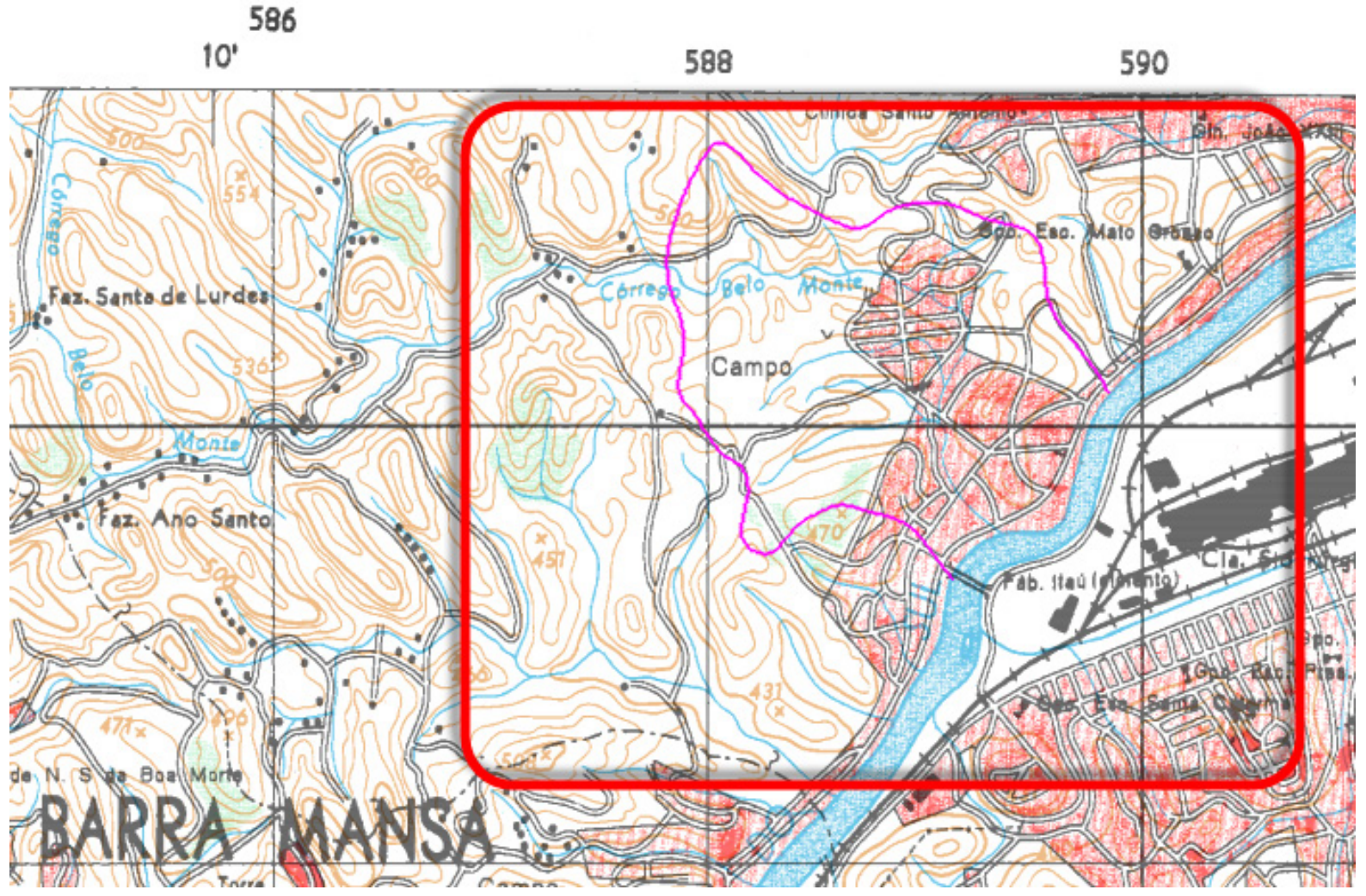

Fonte: Carta Topográfica FL SF-23-Z-A-V-2

Legenda referente a figura 2 .

\begin{tabular}{l|l}
\hline Traço Marrom & Curvas de níveis da Carta Topográfica. \\
\hline Traço Vermelho & Destaca a região a ser analisada. \\
\hline Traço Magenta & Delimitação da Bacia Hidrográfica. \\
\hline Traço Azul Claro & Afluentes contribuintes do rio principal. \\
\hline
\end{tabular}

As figuras 2 e 3 destacam a representação da Carta Topográfica, identificando a delimitação da bacia hidrográfica, o afluente principal e seus contribuintes, em escala 1:50000. Com auxílio das curvas de níveis presentes na Carta Topográfica do IBGE, foi possível delimitar e gerar dados hidrográficos do rio Bugio, localizado no município de Volta Redonda.

A figura 3 destaca a delimitação da Bacia Hidrográfica do rio Bugio, no município de Volta Redonda/ RJ, Brasil. 
Figura 3 - Bacia Hidrográfica do rio Bugio no município de Volta Redonda/RJ, Brasil

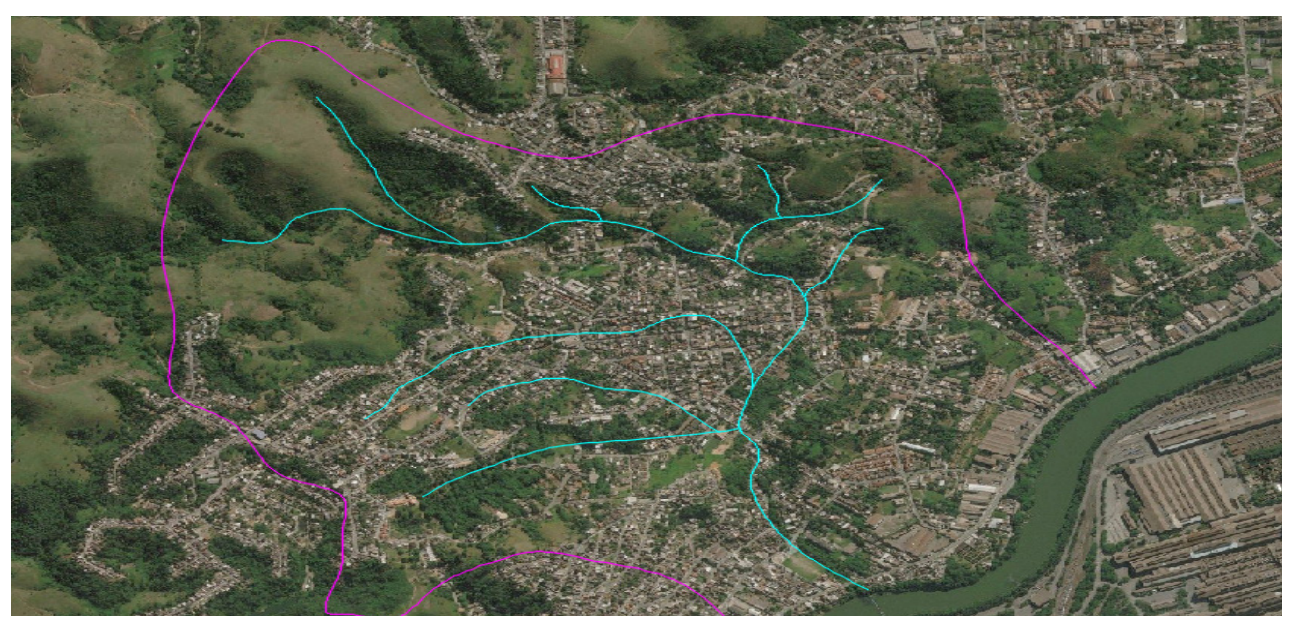

Fonte: 2017 DigitalGlobe CNES (2017) Distribution Airbus DS 2017 Microsoft Corporation bing

A localização do bairro Siderlândia, no município de Volta Redonda/RJ, foi identificada no mapa digital via internet, através de pesquisa no navegador Google Chrome. Com o software AutoCAD, foi possível a sobreposição da imagem de satélite georreferenciada pelo sistema de localização geográfica, com a carta topográfica, possibilitando, dessa forma, a delimitação da Bacia Hidrográfica, identificando-se áreas passíveis de serem recuperadas e não preservadas no entorno do afluente principal e seus contribuintes e também o estudo das faixas marginais de produção e um pré-diagnóstico das condições dos córregos contribuintes do rio Bugio.

Nas figuras 4 e 5, a seguir, com o auxílio do AutoCAD, foi possível demarcar as áreas passíveis de serem recuperadas e não preservadas, delimitando-se a área de cada região.

$\mathrm{Na}$ figura 4, observa-se indicadas em vermelho, as áreas passíveis de serem recuperadas da Bacia Hidrográfica do rio Bugio, em Volta Redonda/RJ.

Figura 4 - Bacia Hidrográfica do rio Bugio com identificação de áreas passíveis de serem recuperadas (vermelho), no município de Volta Redonda/RJ, Brasil

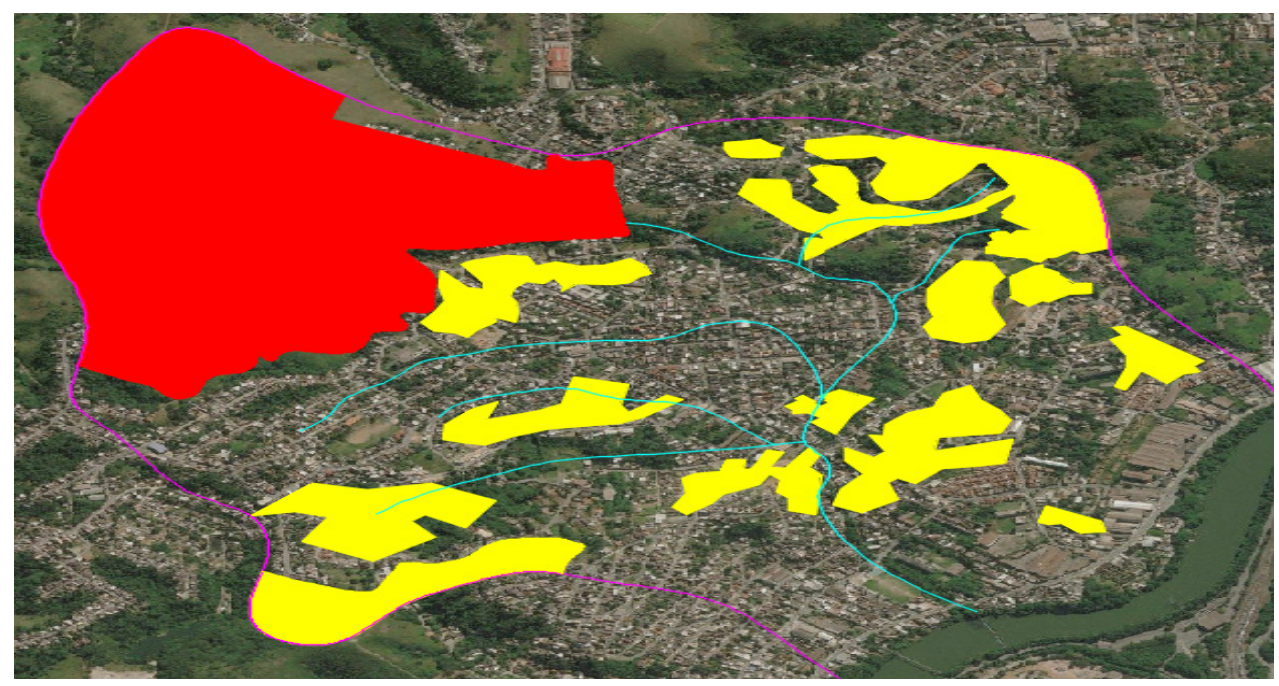

Fonte: 2017 DigitalGlobe CNES (2017) Distribution Airbus DS 2017 Microsoft Corporation bing 
A figura 4 identifica as áreas passíveis de serem recuperadas na bacia hidrográfica, com aproximadamente $1.103 .154,038 \mathrm{~m}^{2}$. A metodologia permite observar que, devido ao adensamento urbano, as áreas indicadas em amarelo são áreas que, embora estejam inseridas na bacia, dificultam a sua recuperação, pois estão circundadas pela malha urbana.

A figura 5 contempla todas as áreas não preservadas da Bacia Hidrográfica do rio Bugio em Volta Redonda/RJ.

Figura 5 - Bacia Hidrográfica do rio Bugio destacando as áreas não preservadas, no município de Volta Redonda/RJ, Brasil

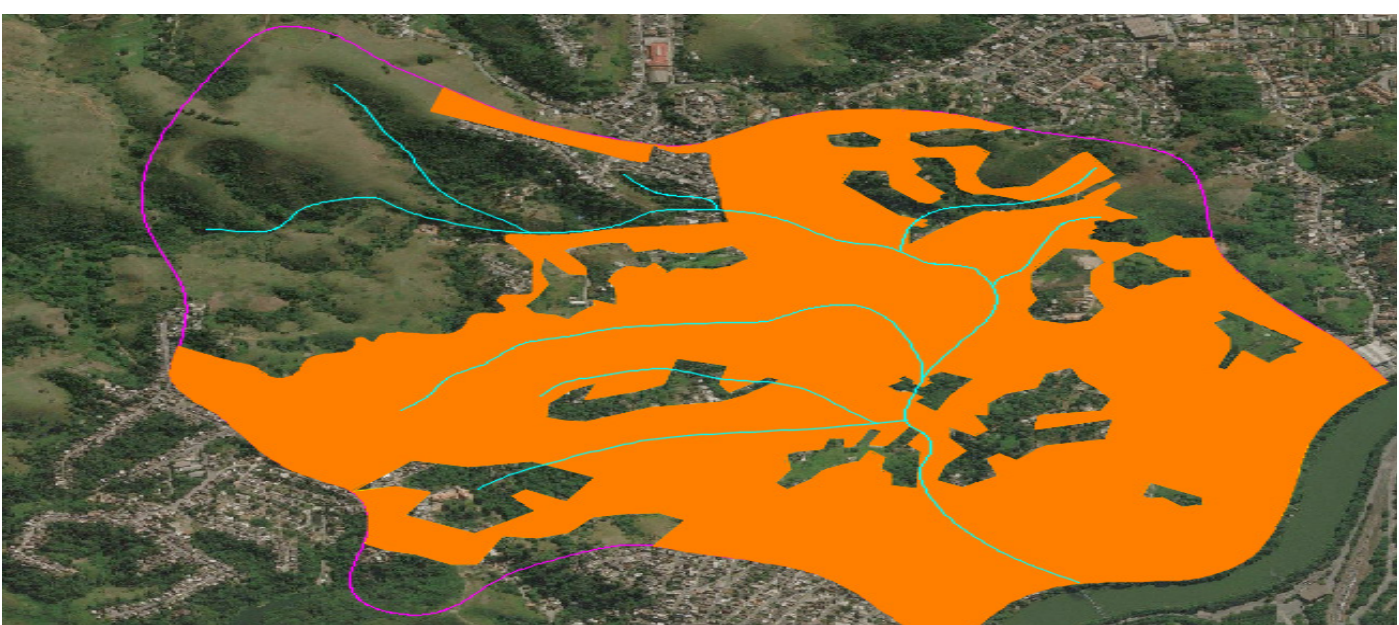

Fonte: 2017 DigitalGlobe CNES (2017) Distribution Airbus DS 2017 Microsoft Corporation bing

A figura 5 identifica toda a região não preservada da Bacia Hidrográfica com, aproximadamente, com $1.819 .701,539 m^{2}$.

A tabela 2 representa numericamente as dimensões obtidas das áreas passíveis de serem recuperadas e não preservadas da Bacia Hidrográfica.

Tabela 2: Dimensionamento das Áreas Estudadas

\begin{tabular}{lll}
\hline ÁREAS & ÁREAS POR M & PERCENTUAL \\
\hline Total & $2.922 .855,577 \mathrm{~m}^{2}$ & $100 \%$ \\
\hline $\begin{array}{l}\text { Área passível de ser } \\
\text { recuperada }\end{array}$ & $611.151,536 \mathrm{~m}^{2}$ & $20,91 \%$ \\
\hline Edificada & $2.311 .704,041 \mathrm{~m}^{2}$ & $79,09 \%$ \\
\hline
\end{tabular}

Fonte: Oliveira (2018)

Com a utilização da metodologia expedita, em uma escala de baixa precisão, foi possível obter informações do uso do solo, tais como: dimensionamento aproximado de áreas passíveis de serem recuperadas e áreas não preservadas, onde a área total da Bacia Hidrográfica apresenta um dimensionamento de $2.922 .855,5772 \mathrm{~m}^{2}$, área passível de ser recuperada com índice de $611.151,5365 \mathrm{~m}^{2}$ e área não preservada com índice de $2.311 .704,041 \mathrm{~m}^{2}$. Através desses dados, será possível a realização do diagnóstico da bacia hidrográfica. 


\section{RESULTADOS}

Por se tratar de proposta em que não se requer grande precisão, as ferramentas desenvolvidas, assim como os dados fornecidos pelo IBGE, fornecem dimensões das áreas descritas com a exatidão de uma escala pequena, ou seja, de pouca precisão. Silva et al. (2016), na avaliação ambiental da sub-bacia do Córrego Vargem Grande em Montes Claros/MG, utilizaram levantamento bibliográfico sobre impactos ambientais, imagem de radar do sensor Shuttle Radar Thematic Mapper (SRTM), disponível no sítio da Embrapa Relevo, e a matriz de Leopold (1971), na qual as informações são dispostas em linhas e colunas que possibilitaram uma amostragem mais real e detalhada da situação encontrada.

Para facilitar o desenvolvimento de aplicação do método, adotou-se escala igual a escala presente da carta topográfica do IBGE. Por ser uma escala de visualização, com atualização das imagens periódicas, apresentando pequenas variações de dimensão, de ordem de metro quadrado, sua imprecisão não interfere no trabalho, uma vez que a expansão urbana não é tão rápida quanto à reposição das imagens. Essa metodologia permitiu obter as dimensões e o percentual das áreas, possibilitando a realização de um diagnóstico local de cada área analisada. Por meio desses resultados, foi possível avaliar o uso do solo e seus possíveis impactos ambientais, o quantitativo populacional da região e as formas de ocupação, auxiliando na tomada de decisão dos gestores municipais e dos órgãos fiscalizadores.

Foi possível identificar a área total da bacia com dimensionamento de $2.922 .855,5772 \mathrm{~m}^{2}$, a área passível a ser recuperada, apresentando $611.151,5365 \mathrm{~m}^{2}$, representando $20,91 \%$ na bacia e a área não preservada, com índice de 2.311.704,041 m², representando 79,09\% na bacia. Na área não preservada, contemplam áreas edificadas e áreas que não permitem a recuperação devido ao adensamento da bacia e malha urbana, tendo como finalidade uma vegetação paisagística.

Os dados obtidos da bacia hidrográfica são consistentes, pois, mesmo utilizando uma ferramenta de baixa precisão, foi possível a coleta de informações para a análise da bacia hidrográfica e o cálculo dos índices do uso e ocupação do solo, tais como: as áreas passíveis de recuperação, áreas degradadas e ocupação em Faixa Marginal de Proteção. Para uma análise mais acurada da área e possível intervenção do Poder Público, é necessária a elaboração de um Estudo de Impacto Ambiental (EIA) nos meios físico, biológico e socioeconômico, conforme disposto na Resolução $n^{\circ} 001 / 86$, do Conselho Nacional de Meio Ambiente, que informa todas as diretrizes gerais para a execução do estudo.

O resultado apresentado demonstra que a utilização das ferramentas indicadas com a aplicação da metodologia expedita na Bacia Hidrográfica do rio Bugio, afluente do rio Paraíba do Sul, apresenta resultados confiáveis que permitem a tomada de decisão de maneira mais ágil pelo Poder Público com vistas à proteção do meio ambiente e, principalmente, dos recursos hídricos existentes.

\section{CONCLUSÃO}

Por ser uma escala de baixa precisão, o método não possibilita uma análise muito detalhada, devido às limitações dos dados e da escala da imagem. Essa ferramenta é específica para tomadas de decisões imediatas ou em curto prazo e difere do método desenvolvido por Brandão (2005), que criou o índice de degradação ambiental (IDA), que possibilita quantificar e classificar temporal e espacialmente as sub-bacias em áreas de "qualidade ambiental alta, moderada, sub-crítica e crítica", auxiliando na gestão territorial pela possibilidade de orientar uma ocupação mais planejada e sustentável do solo. Freitas (2020) argumenta, em sua pesquisa, que o IDA possibilitou a identificação das áreas que mais estão degradadas na Bacia do Rio das Antas (PR) e que a metodologia consegue relacionar os fatores antrópicos com outras variáveis pertinentes à análise em questão. 
Os resultados apresentados mostram que o método possibilita o auxílio aos gestores ambientais e órgãos fiscalizadores através da aplicação de metodologia de fácil acesso e operação, com o intuito de otimizar os trabalhos dos técnicos durante o levantamento de diagnósticos, na tomada de decisão em ações de fiscalização, monitoramento e atividades que impactam as bacias hidrográficas. Para o diagnóstico ambiental de grandes áreas e bacias hidrográficas muito extensas e com alto grau de antropismo, o método não é recomendado, pois se mostra limitado a microbacias no que tange ao aspecto espacial.

\section{REFERÊNCIAS}

BRANDÃO, Marcelo Henrique de Melo. Índice de Degradação Ambiental na bacia hidrográfica do rio do Peixe/PB. 2005. Tese (Doutorado em Geociências) - Universidade Federal de Pernambuco, Recife, 2005.

BRASIL. Lei Federal $n^{\circ}$ 6.938/81. Dispõe sobre a Política Nacional do Meio Ambiente, seus fins e mecanismos de formulação e aplicação, e dá outras providências. Brasília, DF: Presidência da República, 1981.

BRASIL. Lei Federal n 9.433, de 8 de janeiro de 1997. Institui a Política Nacional de Recursos Hídricos, cria o Sistema Nacional de Gerenciamento de Recursos Hídricos, regulamenta o inciso XIX do art. 21 da Constituição Federal, e altera o art. $1^{\circ}$ da Lei $n^{\circ} 8.001$, de 13 de março de 1990, que modificou a Lei n 7.990, de 28 de dezembro de 1989. Brasília, DF: Presidência da República, 1997.

BRASIL. Lei Federal $\mathbf{n}^{\circ}$ 12.651/12. Dispõe sobre a proteção da vegetação nativa; altera as Leis nos 6.938, de 31 de agosto de 1981, 9.393, de 19 de dezembro de 1996, e 11.428, de 22 de dezembro de 2006; revoga as Leis nos 4.771, de 15 de setembro de 1965, e 7.754, de 14 de abril de 1989, e a Medida Provisória no 2.166-67, de 24 de agosto de 2001; e dá outras providências. Brasília, DF: Presidência da República, 2012.

BRASIL. Ministério do Meio Ambiente. Resolução CONAMA, nº 001 de 23 de janeiro de 1986. Brasília, DF: Ministério da Educação, 1996.

CARDOSO, Christiany Araujo; DIAS, Herly Carlos Teixeira; SOARES, Carlos Pedro Boechat; MARTINS, Sebastião Venâncio. Caracterização Morfométrica da Bacia Hidrográfica do Rio Debossan, Nova Friburgo, RJ. Revista Árvore, Viçosa-MG, v. 30, n. 2, p. 241-248, 2006.

FUNDAÇÃo ESTADUAL DE ENGENHARIA DO MEIO AMBIENTE. Perfil do Município de Volta Redonda. Rio de Janeiro: FEEMA, 1991. 98p.

FREITAS, Andreza Rocha de. Degradação ambiental na bacia hidrográfica do Rio das Antas, Sudeste do Paraná: análise quantitativa e qualitativa mediante a utilização da metodologia do IDA. Revista GEOgrafias, v. 28, n. 1, 2020.

LEOPOLD, L. B. A procedure for evaluating environmental impact. Geological Survey Circular, Washington, n. 645, p. 1-16, 1971.

MAGALHÃES, Cristiane Ramos. Bacia Hidrográfica como referência de Planejamento e Expansão Urbana para as Cidades no século XXI. 2013. Dissertação (Mestrado em Engenharia Urbana) - Universidade Federal do Rio de Janeiro, Escola Politécnica, Programa de Engenharia Urbana, Rio de Janeiro, 2013.

MENEZES, Paulo Márcio Leal de; COELHO NETO, Ana Luiza. Escala: estudo de conceitos e aplicações. Universidade Federal do Rio de Janeiro, Igeo - Dep. Geografia, Rio de Janeiro, 1999. Disponível em: http://www.geocart.igeo.ufrj.br/pdf/trabalhos/Escala_Conceitos_Aplic.pdf. Acesso em: 05 jun. 2017. 
MELO, Danilo H. C. T. B. et al. Aquisição e Leitura da Carta Topográfica Digital do IBGE. Geografia (Londrina) v. 23, n. 1. p. $191-204$, jan/jun, 2014.

OLIVEIRA, Mariana Avila Corrêa Cardoso de. Tabela 2: Dimensionamento das Áreas Estudadas, representação numérica das dimensões obtidas das áreas passíveis de serem recuperadas e não preservadas da Bacia Hidrográfica, 2018.

RIO DE JANEIRO. Decreto Estadual $\mathbf{n}^{\circ}$ 42.356, de 16 de março de 2010. Anexo 2: Dispõe sobre o Tratamento e a Demarcação das Faixas Marginais de Proteção nos Processos de Licenciamento Ambiental e de Emissões de Autorizações Ambientais no Estado do Rio de Janeiro e dá outras providências. Disponível em: http://200.20.53.3:8081/cs/groups/public/documents/document/zwff/mde0/ edisp/inea_014685. pdf Acesso em: 07 maio 2017.

SILVA, Renato Ferreira da; SANTOS, Vanderson Aguiar; GALDINO, Sanndy Maria Gonçalves. Análise dos impactos ambientais da Urbanização sobre os recursos hídricos na sub-bacia do Córrego Vargem Grande em Montes Claros-MG. Caderno de Geografia, v. 26, n. 47, 2016.

SPECK, Henderson José. Proposta de método para facilitar a mudança das técnicas de projetos: da prancheta à modelagem sólida (CAD) para empresas de engenharia de pequeno e médio porte. 2005. Tese (Doutorado em Engenharia de Produção) - Universidade Federal de Santa Catarina, Programa de Pós-Graduação em Engenharia de Produção, 2005.

TUCCI, Carlos E. M.; MENDES, Carlos André. Avaliação Ambiental Integrada de Bacia Hidrográfica. Ministério do Meio Ambiente / SQA, Brasília: MMA, 2006.

VOLTA REDONDA. Decreto Municipal $\mathbf{n}^{\circ}$ 978/78. Regulamenta o Sub-zoneamento da ZH-X, criada pelo Decreto n 942/77 e dá outras providências. Disponível em: www.voltaredonda.rj.gov.br/smp/mod/dcu/ decretos/decretos/Dec978-78.pdf Acesso em: 15 maio 2017. 